\title{
REVIEW \\ Reckless Behavior in Adolescence: A Developmental Perspective
}

\author{
JEFFREY ARNETT \\ Universily of Missouri-Columbia
}

\begin{abstract}
A developmental theory of reckless behavior among adolescents is presented, in which sensation seeking and adolescent egocentrism are especially prominent factors. Findings from studies of automobile driving, sex without contraception, illegal drug use, and minor criminal activity are presented in evidence of this. The influence of peers is then discussed and reinterpreted in the light of sensation seeking and adolescent egocentrism. Socialization influences are considered in interaction with sensation seeking and adolescent egocentrism, and the terms narrow and broad socialization are introduced. Factors that may be responsible for the decline of reckless behavior with age are discussed. 1992 Acadernic Press, Inc.
\end{abstract}

I would that there were no age between ten and three-andtwenty, or that youth would sleep out the rest; for there is nothing in between but getting wenches with child, wronging the ancientry, stealing, fighting ...

William Shakespeare, "The Winter's Tale," Act III, Scene 3

Adolescence bears a heightened potential for recklessness compared to other developmental periods in every culture and in every time. The forms that this proclivity takes, and even whether it is allowed expression at all, depend on the characteristics of the particular culture and the particular time. "Wronging the ancientry" may not be a social problem in the late 20th century, but new forms of recklessness have arisen in our time-driving a car while under the influence of alcohol, for example. Other forms of recklessness appear and reappear across time: the delinquency and sexual recklessness alluded to centuries ago in the above quote are characteristic of adolescence in our age as well. Contemporary theory and research on adolescence have emphasized that the storm and stress popularly thought to be characteristic of adolescence have been exaggerated and that adolescence is not necessarily a tumultuous period of development, but it remains true that adolescents are overrepresented statistically in virtually every category of reckless behavior.

Correspondence and reprint requests should be addressed to Jeffrey Arnett, Ph.D., Department of Human Development and Family Studies, 31 Stanley Hall, University of Missouri-Columbia, Columbia, MO 65211. 
Various forms of reckless behavior have been studied, but thus far there have been few attempts to identify the factors that might underlie all varieties of recklessness or to explain why reckless behavior is especially prevalent in adolescence. In what follows, threads from various areas that bear directly or indirectly on reckless behavior in adolescence will be drawn together in an effort to establish a developmental understanding of it.

Studies in this area have used a number of terms to describe behavior similar to what is discussed here as reckless behavior. For example, Jessor and Jessor (1977; Jessor, 1987a,b, 1990) have discussed what they term "problem behavior." This includes behavior of interest here, such as drug use and minor criminal activity, as well as sexual activity (with or without contraceptives) and alcohol consumption (at any level). The term reckless behavior is preferred here because it carries stronger connotations of the potential for negative consequences-serious personal injury or death, an unwanted pregnancy, or arrest and conviction by the legal system. Thus, while sexual activity among adolescents may be "problem behavior," in the sense that many adults do not approve of it, it is not considered reckless behavior here unless they engage in sex without the use of contraception. Similarly, alcohol consumption is defined as problem behavior in that it is discouraged for adolescents in the U.S. below the age of 21 , but it would not be considered reckless behavior here unless it were combined with automobile driving or some other activity that raised the stakes of the potential consequences.

Other forms of reckless behavior have been referred to using the term "risk taking." However, "risk" is a term that has been used to refer not only to acts with serious potential consequences, but also to economic calculations and gambling judgments, where the focus is on monetary gain or loss, and to behavior such as truancy and willingness to volunteer for psychological experiments, where even the worst outcome is not profound. "Recklessness" is also preferred to "thrill seeking," since many activities (e.g., parachute jumping, rafting, rock climbing) may be thrilling but also socially acceptable, and the potential for serious consequences resulting from them is slight. Danger is recognized but deliberately minimized; with reckless behavior, on the contrary, precautions that could easily be taken are not. Still, the terms overlap considerably, and the ideas presented here are intended to apply to most forms of problem behavior and risk taking.

Adolescence will be discussed here as extending from puberty to the early 20 's. This is a wider range than typically defined, but if adolescence is the time from the beginning of puberty until adult responsibilities are taken on, it is an appropriate range for our culture. Adolescence is a bridge between childhood and adulthood, during which the individual is 
gaining further education and training that will enable him/her to fulfill a useful role in adult society. The demarcation of the end of adolescence must always be somewhat arbitrary, since in most societies there is likely to be variance among individuals in the completion of that period of preparation. But certainly a young person who is in college at someone else's expense has not yet completed adolescence, nor has a young person who has chosen not to attend college but is working a variety of short-term jobs while trying to decide upon a future direction and living with his/her parents during this period. In our culture, establishing an independent household is delayed until the early 20 's for most peopletoday only $24.3 \%$ of 18 - to 24 -year-olds run their own households (U.S. Department of Education, 1988) -and in general adolescence cannot be said to have been completed until this responsibility is assumed.

The goal of this paper is fivefold: (1) to argue that a variety of forms of reckless behavior have common underlying factors that are especially characteristic of adolescence as a developmental stage; (2) to present evidence indicating that sensation seeking and adolescent egocentrism are two of the most influential of these factors; (3) to reinterpret the influence of peers in the light of sensation seeking and adolescent egocentrism; (4) to consider the interactions between sensation seeking/egocentrism and socialization; and (5) to suggest directions for research on the course of reckless behavior from adolescence to young adulthood.

\section{FORMS OF RECKLESS BEHAVIOR}

In what ways does reckless behavior in adolescence manifest itself in our time? Some of the most prevalent forms are driving at high speeds and while under the influence of alcohol, engaging in sex without using contraception, using illegal and potentially dangerous drugs, and engaging in minor criminal activity. Each of them, of course, has unique features and a complex network of causes-inexperience may play a role in driving fatalities, etc. The model presented here is intended to delineate the developmental foundation of causes that these different forms of reckless behavior have in common, in addition to their unique characteristics. All of them are more common among adolescents than among any other age group. Furthermore, the theory is intended to apply to other, less common forms of reckless behavior, in addition to the four categories used here for illustration.

\section{Driving at High Speeds and While Drunk}

Reckless driving behavior is among the most pervasive and damaging social problems of American society, and it is a problem that is especially 
characteristic of adolescents. Adolescents are not only more likely than those in other age groups to drive after drinking (Jonah \& Wilson, 1984), but they also drive faster, drive closer to vehicles in front of them, and use seat belts less frequently (Jonah, 1986). This is a lethal combination. In 1986, adolescents (aged 16-24) comprised 18.7\% of the licensed drivers, but $38.7 \%$ of the drunk drivers involved in fatal accidents (U.S. Bureau of the Census, 1987). Drivers aged 16-19 have the highest rate of involvement in accidents resulting in injuries (Jonah, 1984) and fatalities (Williams, 1985) of any age group, and over half of the fatally injured drivers aged 16-25 have been found to have blood alcohol levels above the legal limit (Beirness, Haas, Walsh, \& Donelson, 1985). Automobile accidents are the leading cause of death among people aged 16 to 24 (U.S. Department of Education, 1988).

\section{Sex without Contraception}

In recent years in the U.S. over a million unmarried girls aged 15 to 19 have become pregnant each year, the highest number and the highest rate of premarital pregnancies of any age group. These statistics are predictable in light of the finding that over two-thirds of unmarried girls have had sex by age 19, and only one-third of sexually active girls aged 15-19 use contraceptives consistently (Zelnik \& Kantner, 1980). Young women aged 15-24 have both the highest abortion rate (Tietze, 1983) and the highest out-of-wedlock birth rate (U.S. Department of Education, 1988) of any age group.

Illegal Drug Use

The use of illegal drugs can be considered reckless in a number of different ways. The more powerful drugs, such as heroine and cocaine, carry the risk of a fatal overdose. Another risk is contained in the fact that most illegal drugs are potentially addictive. And even the more benign illegal drugs, such as marijuana, carry by definition the risk that the user will be arrested and prosecuted for using them.

Adolescents have the highest rate of use of virtually every kind of illegal drug. Persons $12-25$ years old are five times more likely than persons over 26 to be current users of marijuana; five times more likely to be current users of hallucinogens; and six times more likely to be users of stimulants (U.S. Bureau of the Census, 1987). Heroin use is also highest among 18- to 25-year-olds (Fishburne, Abelson, \& Cisin, 1980). Furthermore, drug use among adolescents is not restricted to a phase in early adolescence; use of alcohol, marijuana, and cocaine increases throughout early to mid adolescence and declines sharply only after the early 20 's (Gans, Blyth, Elster, \& Gaveras, 1990). 


\section{Delinquency and Crime}

Studies of the prevalence of delinquency and criminal activity such as minor theft and vandalism have found the proportion of adolescents who have recently engaged in such activity in some form to range from about one-quarter (Levine \& Kozak, 1979) to over three-quarters (Farrington, 1989) depending on factors such as the time interval in question and urban or nonurban location. The prevalence rates in this area are especially high in early adolescence (Farrington, 1989; Levine \& Kozak, 1979; Murphy, 1986). Statistics of arrests underestimate the prevalence of minor criminal activity among adolescents, as offenders in this age group are more likely than older offenders to be cautioned rather than prosecuted (Murphy, 1986). Nevertheless, arrests for offenses such as vandalism and larceny theft are also far more common for adolescents than for adults (Wilson \& Herrnstein, 1985, p. 130). What is true for minor criminal activity is also true for crime generally, with regard to age differences, although most other crime is less normative and more characteristic of a highly reckless subgroup of adolescents. Even when factors such as education, occupation, family size, and quality of home life are taken into account, the association of age with criminal behavior is preeminent (Rowe \& Tittle, 1977).

\section{MULTIPLE RECKLESS BEHAVIOR}

Among adolescents, a propensity for recklessness tends to be reflected not just in one type of behavior, but in a variety of forms. Elster, Lamb, and Tavare (1987) found that among a national sample of adolescent males, those who had fathered a child by age 19 were also more likely to report marijuana use, police involvement, shoplifting, and antisocial aggression. Similar findings were reported for a national sample of adolescent females: self-reported behaviors at age 15-17 such as fighting and use of marijuana and other drugs were predictive of bearing a child by age 21 (Elster, Ketterlinus, \& Lamb, 1989). Other studies have noted correlations between delinquency and drug use (Levine \& Singer, 1988); premarital pregnancy and drug use (Yamaguchi \& Kandel, 1987); sexual behavior, delinquency, drug use, and school misbehavior (Hundleby, 1987); and problem drinking, marijuana use, delinquency, and early sexual intercourse (Donovan, Jessor, \& Costa, 1988). An understanding of any of these problems might be fostered by identifying factors that underlie all of them.

The focus in this paper is on reckless behavior from a developmental perspective. Reckless behavior is analyzed as a common feature of the adolescent age period, not as aberrant or deviant behavior and not as an indication of psychopathology. These kinds of behavior certainly are ab- 
errant and deviant when set against the adult standard of acceptable behavior, but with half or more adolescents reporting that they have experienced drunk driving (Arnett, 1990a), sex without contraception (Zelnik \& Kantner, 1980), illegal drug use (U.S. Department of Education, 1988), and some form of minor criminal activity (Farrington, 1989), reckless behavior becomes virtually a normative characteristic of adolescent development. It is true that reckless behavior may be in some cases a reflection of psychopathology (Brill \& Cristie, 1974) or of pathogenic family conditions (Dembo, Dertke, laVoie, \& Bonders, 1987), or at least partly a response to parental neglect, hostility, or absence (Davis \& Cross, 1973; Hansson, O'Conner, Jones, \& Blocker, 1981; Johnson, Shontz, \& Locke, 1984; Stern, Northmn, \& Van Slyck, 1984). But the very prevalence of reckless behavior calls into question the common assumption that it necessarily arises from pathological personal characteristics or from pathogenic socialization practices or that reckless behavior is always deviant behavior for adolescents. Because reckless behavior is so pervasive among adolescents, other explanations are called for that explain it in terms of factors that are features of adolescence as a developmental stage. On the other hand, it is not being suggested here that all adolescents are reckless, only that adolescents as a group engage in a disproportionate amount of reckless behavior.

\section{FACTORS PROMOTING RECKLESS BEHAVIOR}

\section{Sensation Seeking}

In part, reckless behavior in adolescence can be viewed as a manifestation of what Zuckerman (1979a) terms "sensation seeking." Sensation seeking is a dimension of personality that is characterized by "the need for varied, novel, and complex sensations and experiences and the willingness to take physical and social risks for the sake of such experiences" (Zuckerman, 1979a, p. 10). The implication of this is that people who are high in sensation seeking are willing, even eager, to engage in reckless behavior in order to produce intense and/or novel sensation. And adolescents, as a group, are especially high in sensation seeking. Scores on the Sensation Seeking Scale (Zuckerman, Eysenck, \& Eysenck, 1978) are highest at age 16 (the lowest age included in the development of the scale), and there is a steady decline with age.

In the Sensation Seeking Scale (SSS), there are four subscales. The Thrill and Adventure Seeking (TAS) subscale concerns the individual's inclination to engage in novel and intense recreation such as water skiing or mountain climbing. The Disinhibition (Dis) subscale concerns social drinking, enjoyment of loud and lively parties, and sexual attitudes. Items on the Boredom Susceptibility (BS) subscale tap the degree of the indi- 
vidual's aversion to repetition, routine, and unexciting people. The Experience Seeking (ES) subscale focuses on desire for travel, pursuit of a nonconforming way of life, and generally the seeking of unusual experiences through the mind and senses. Age differences are strongest for the TAS and Dis subscales; for females, there is a steady decline with age on all subscales, but for males only scores on the TAS and Dis subscales decline significantly with age (Zuckerman et al., 1978).

Sensation seeking has been found to be directly and indirectly related to reckless behavior in a variety of studies. One study has confirmed its relation to drunk driving among adolescents (Arnett, 1990a), and it has also been shown in separate studies to be related to alcohol use (Schwartz, Burkhart, \& Green, 1978; Zuckerman, Bone, Neary, Mangelsdorff, \& Brustman, 1972) and to dangerous driving practices (Zuckerman and Neeb, 1980). An early study (Goldstein \& Mosel, 1958) found positive attitudes toward speed and risk taking while driving to be predictive of the number of traffic violations and accidents in which the individual had been involved. Sensation seeking has also been found to be related to sex without contraception among adolescents (Arnett, 1990b) and to a variety of sexual experiences (Zuckerman et al., 1972; Zuckerman, Tushup, \& Fenner, 1976). In the area of drug use, Satinder and Black (1984) found sensation seeking to be related to the use of marijuana and LSD on all four subscales of the SSS and on the total score. Also, SSS scores have been found to be related to the number of different drugs used by drug abusers (Spotts \& Shontz, 1984; Sutker, Archer, \& Allain, 1978). Indirectly, adolescents report sensation seeking motives-_" "out of curiosity;" "to see what it was like" -overwhelmingly as their strongest motive for trying illegal drugs (Levine \& Kozak, 1979). With regard to crime and delinquency, Perez and Torrubia (1985) reported a significant relation between sensation seeking and antisocial behavior for a sample of Spanish medical students for the total SSS score and all four subscales. Also, use of an early form of the SSS indicated that prisoners who were high in sensation seeking were guilty of more criminal behavior, for both males (Farley, 1973) and females (Farley \& Farley, 1972). Indirectly, Wilson and Herrnstein (1985), noting the small potential gains involved in property crimes committed by juveniles, suggest that these adolescents are motivated partly by "sheer adventurousness" (p. 133), which may be taken to indicate a high level of sensation seeking.

The biological basis of sensation seeking, which has received considerable research attention (see Zuckerman, 1984), provides further insight into the prevalence of reckless behavior during adolescence. Table I summarizes the evidence connecting biological factors to sensation seeking and reckless behavior. Scores on the SSS have been found to be related to Average Evoked Potential (AEP) augmenting-reducing, which is a 
TABLE I

Biological Factors in Sensation Seeking and Reckless Behavior

\begin{tabular}{|c|c|c|c|}
\hline Biological factor & $\begin{array}{c}\text { Age } \\
\text { differences }\end{array}$ & $\begin{array}{l}\text { Relation to } \\
\text { sensation } \\
\text { seeking }\end{array}$ & $\begin{array}{l}\text { Relation to } \\
\text { reckless } \\
\text { behavior }\end{array}$ \\
\hline AEP augmenting-reducing & $\begin{array}{l}\text { Younger augment; } \\
\text { older reduce }\end{array}$ & $\begin{array}{l}\text { SS positively } \\
\text { related to } \\
\text { augmenting }\end{array}$ & $\begin{array}{l}\text { Augmenting related } \\
\text { to alcohol and } \\
\text { depressant drug } \\
\text { use, delinquency, } \\
\text { criminality }\end{array}$ \\
\hline MAO levels & $\begin{array}{l}\text { Increase with age } \\
\text { or no difference }\end{array}$ & $\begin{array}{l}\text { SS negatively } \\
\text { related to } \\
\text { MAO levels }\end{array}$ & $\begin{array}{l}\text { Low MAO related } \\
\text { to drug and } \\
\text { alcohol use, } \\
\text { criminality }\end{array}$ \\
\hline Sex hormone levels & $\begin{array}{l}\text { Testosterone } \\
\text { declines with } \\
\text { age }\end{array}$ & $\begin{array}{l}\text { Dis subscale } \\
\text { positively related } \\
\text { to testosterone } \\
\text { and estrogen } \\
\text { levels }\end{array}$ & $\begin{array}{l}\text { Testosterone } \\
\text { levels related } \\
\text { to violent crime, } \\
\text { sexual attitudes } \\
\text { and experience }\end{array}$ \\
\hline
\end{tabular}

measure of the brain's tendency to respond to a strong visual or auditory stimulus by augmenting the stimulus (increasing its intensity) or reducing it (responding less to a highly intense stimulus than to a slightly less intense stimulus). Augmenting is considered to indicate a "strong" nervous system, while reducing represents a "weak" one (Zuckerman, 1984). A number of studies (Buchsbaum, 1971; Coursey, Buchsbaum, \& Frankel, 1975; Lukas \& Siegel, 1981) have shown SSS scores to be positively related to augmenting, especially the Disinhibition subscale, and it has also been shown that younger subjects tend to be augmenters, while older subjects tend to be reducers (Buchsbaum, 1974). Also, augmenting has been found to be related to delinquency (Silverman, Buchsbaum, \& Stierlin, 1973) and criminality (Blackburn, 1978; Emmons \& Webb, 1974), which indicates a common biological basis for sensation seeking and these manifestations of reckless behavior. More directly, both augmenting and high scores on the Disinhibition subscale have been found in sociopaths, delinquents, and drug users (Zuckerman, 1984).

Monoamine oxidase (MAO) is an enzyme that is related to the synaptic sensitivity of neurons; the higher the MAO level, the less sensitive the neurons. Platelet MAO levels have been found to be negatively correlated with SSS scores (Murphy, Belmaker, Buchsbaum, Wyatt, Martin, \& Ciaranello, 1977; Schooler, Zahn, Murphy, \& Buchsbaum, 1978); high sensation seekers tend to have low MAO levels and low sensation seekers tend to have high MAO levels. In relation to reckless behavior, a study of 18-year-old Swedish draftees found that low-MAO males were higher in 
SSS scores than high-MAO males, and the low-MAO males were also more likely to report reckless behavior such as drug use and criminality (von Knorring, Oreland, \& Winbald, 1983). Low MAO levels are also characteristic of alcoholics (Major \& Murphy, 1978) and chronic marijuana users (Stillman et al., 1978). Since MAO is negatively correlated with sensation seeking and sensation seeking is negatively correlated with age, one might reasonably expect to find that MAO levels increase with age; one study (Robinson, Davis, Nies, Ravaris, \& Sylvester, 1971) bears this out, although another (Murphy, Wright, Buchsbaum, Nichols, Costa, \& Wyatt, 1976) reports no age differences in MAO levels.

Sensation seeking has also been demonstrated to be related to levels of sex hormones. Daitzman, Zuckerman, Sammelwitz, and Ganjam (1978) found levels of androgen and estrogen to be positively related to scores on the Dis subscale, even when age, height, weight, and recency of orgasm were controlled. Testosterone levels, like sensation seeking, decline steadily with age from the 20's onward (Harman, 1978). Testosterone levels have also been found to be related directly and indirectly to reckless behavior. Directly: although there is not a clear correlation between aggressiveness and testosterone in the normal range, male prisoners who have committed especially violent crimes tend to have higher testosterone levels than other prisoners (Rose, 1978). Indirectly: Daizman and Zuckerman (1980) report that testosterone level is positively correlated with variety of sexual experiences and with permissiveness in sexual attitudes.

It is worth noting in this context that there are clear sex differences in sensation seeking, the reckless behavior associated with it, and the biological factors that underlie it. Scores on the SSS are higher among males than among females at all ages (Zuckerman et al., 1978). Males are higher on most types of reckless behavior (including drunk driving (Clark \& Midanik, 1980), drug use (U.S. Bureau of the Census, 1987, p. 112), and property crimes such as vandalism (Wilson \& Herrnstein, 1985)). Males are also different than females on some biological markers in ways that point to a higher level of sensation seeking. They have higher testosterone levels (Daitzman \& Zuckerman, 1980) and lower levels of platelet MAO (Murphy et al., 1976; Robinson et al., 1971), although the findings concerning the relation between augmenting-reducing and gender are mixed (see Zuckerman, 1983).

It should be added that there are certain psychometric limitations of the Sensation Seeking Scale, in its construction and in how it has been used. The phrasing of some items is awkward and lends itself to misreading, and certain words in it are anachronistic (e.g., "hippies," "jet set") and reflective of the late 1960s-early 1970s period when the scale was developed. Also, some of the studies that have purported to demonstrate the relationship between sensation seeking and behavior have failed to ac- 
knowledge the potential for item overlap between the SSS and the behavior it is said to predict. For example, numerous studies (Satinder \& Black, 1984; Spotts \& Shontz, 1984; Sutker et al., 1978) have reported a significant relation between drug use and scores on the SSS, while failing to note that 3 of the 40 items on the SSS directly concern drug use and apparently neglecting to delete those items. Nevertheless, the SSS has proven useful in establishing the personality trait of sensation seeking and its relation to a wide range of behaviors. Sensation seeking is rich as a theoretical construct and holds the potential for further operationalizing in relation to reckless behavior. (See Arnett (1992) for an alternative scale.)

In summary, sensation seeking may form a large part of the foundation of reckless behavior among adolescents. Scores on the Sensation Seeking Scale are highest in adolescence, and research evidence suggests that sensation seeking is related to various forms of reckless behavior. The biological factors related to sensation seeking-Average Evoked Potential, MAO levels, and gonadal hormones - help to explain the particular intensity of sensation seeking (and, in turn, of reckless behavior) during adolescence.

\section{Cognitive Factors}

In some respects, cognitive development is considered to be complete by the time the individual reaches mid adolescence. In Piaget's formulation, the stage of formal operations begins at age 12-13 and is consolidated, if not complete, by the age of 15-16. Research has accumulated, however, to show that the attainment of formal operations is not nearly as universal as was once thought (Flavell, 1985) and that even adults who possess it may use it only in special circumstances (Keating, 1980; Moshman, 1979). Adults are for the most part not entirely rational thinkers, and the deficiencies of reasoning that afflict adults are even more acute among adolescents (Kuhn, Phelps, \& Walters, 1985).

Chief among these deficiencies, for an understanding of reckless behavior in adolescence, may be Elkind's (1967, 1968, 1985) conception of adolescent egocentrism. Egocentrism among younger children is characterized, in Piagetian theory, by a failure to differentiate between subject and object, a failure to understand clearly where the self ends and the other begins. In Elkind's view, this is a cognitive deficiency that has not been entirely overcome by adolescence.

In adolescence, the advent of formal operations confers the ability to consider thoughts as objects, both one's own thoughts and the thoughts of others. But egocentrism persists: adolescents are likely to confuse the two, so that they are prone to attribute to others many of the thoughts that 
are in fact their own. In particular, they may believe that others are as preoccupied with their behavior and appearance as they are; they construct an imaginary audience, in Elkind's terminology, that is constantly monitoring and evaluating their behavior.

How is this related to reckless behavior? The existence of the imaginary audience leads adolescents to conclude that there is something unique and unparalleled about their lives; it must be so, since so many others are preoccupied with their behavior. This, in turn, leads to a conviction that-by virtue of the fact that their lives are so exceptional-they are invulnerable to the consequences of reckless behavior. As Elkind puts it, "Perhaps because he believes he is of importance to so many people, the imaginary audience, he comes to regard himself . . . as something special and unique. Only he can suffer with such agonized intensity, or experience such exquisite rapture . . This belief in personal uniqueness becomes a conviction that he will not die, that death will not happen to him" (1967, p. 1031). This is the personal fable, "a story which he tells himself and which is not true"' (p. 1031).

The concept of the personal fable has important applications to reckless behavior in adolescence. But Elkind puts more emphasis on the imaginary audience than on the personal fable in his theory of adolescent egocentrism, so the personal fable bears some expansion and elaboration here. First, it is necessary to describe how the attainment of formal operations fosters the development of the personal fable. One of the hallmarks of formal operations is that there is a new conception of the real vs the ideal. Adolescents are capable of thinking in terms of hypothetical situations to a degree that younger children are not. This fosters the idealism that is highly characteristic of adolescents; they are capable of imagining an ideal world, a world free from the multiple ills that afflict the present one. As Piaget notes, the egocentrism of the adolescent makes it difficult for him/ her to recognize the inevitable real-world impediments to idealistic visions of how things ought to be: "Adolescent egocentricity is manifested by a belief in the omnipotence of reflection, as though the world should submit itself to idealistic schemes rather than to systems of reality. It is the metaphysical age par excellance: the self is strong enough to reconstruct the universe and big enough to incorporate it" (Piaget, 1967, p. 64).

Applied to adolescents on a personal level, it might be argued that this expanded imaginative capacity inspires an ideal vision of their own lives. In the same way they can imagine a just and contented world, they may imagine the course of their lives as smooth and sure, an untrammeled path to success and happiness. Clearly, that ideal does not include being afflicted with disasters. And in the same way that the adolescent's conception of an ideal society overlooks the potential flaws in it, and does not follow competely the complex implications and consequences of it, so the 
adolescent's conception of the course of his own life is unsullied by the possibility that some calamity will befall him as a consequence of behaving recklessly. Adolescents are not fully aware that the world inherently holds the potential for irremediable tragedy as well as for ultimate triumph. The personal fable is precisely the adolescent's conviction that he/she is exempt from the disastrous consequences that sometimes result-for others-from reckless behavior.

Another, related way that cognitive factors can be understood to play a role in reckless behavior is in the adolescent's capacity for probability reasoning. It is possible to think of reckless behavior as resulting partly from a failure of probability reasoning. The personal fable may underlie this failure. One could say that the personal fable leads adolescents to distort the perceived risk of a given behavior in their favor: one set of probabilities applies to others, and another, unique set applies to themselves. So, for example, in considering the risks of driving while under the influence of alcohol, an adolescent may consider the possibility of getting a ticket or getting into an accident to be relatively high for others, relatively low or nonexistent for him/herself. As Piaget and Inhelder (1975) point out, in every judgement of probability there is a reference, implicit or explicit, to a system of distributions or frequencies. Adolescents' perceptions of these systems are skewed by their desire for sensation and by the personal fable that convinces them of their immunity from disaster.

Understanding probability and chance is one of the most sophisticated and difficult mental challenges there is, even for the person who has reached formal operations. In contrast to deductive determinations, for which a certain answer is obtainable, the outcomes of events involving probability are, by their very nature, uncertain (Piaget \& Inhelder, 1975). Even if one knows that an event has a $90 \%$ chance of occurring under a given set of conditions, on a particular occasion it is impossible to say with absolute certainty that the event will occur. It is this elusive quality of probability reasoning that makes it especially vulnerable to the distortions of egocentrism. If Piaget and Inhelder (1975) are correct, the adolescent contemplating some form of reckless behavior has in mind a system of distributions or frequencies that describe the likelihood that the contemplated act will result in a disastrous outcome. The probability judgement of adolescents is poor (Ross \& DeGrot, 1982; Wavering, 1984); but, even if an adolescent were exceptionally proficient at estimating probabilities, on a given occasion the likelihood of disaster resulting from drunk driving, or sex without contraception, or illegal drug use, or delinquency/crime is, in fact, statistically small-even when applied to others. Applied to the self, and seen through the dual lens of sensation seeking and egocentrism, the perceived probability fades even further.

Tversky and Kahneman (1973; Kahneman \& Tversky, 1972) describe 
two common heuristics for judging probability, both of which have applications in this context. Probability reasoning is inherently difficult, they note, and so when faced with a task that requires it, people employ heuristics to assess them. One of these heuristics they term representativeness. This refers to the tendency to judge an event as probable "to the extent that it represents the essential features of the parent population ... When judging the probability of an event by representativeness, one compares the essential features of the event to those of the structure from which it originates" (Tversky \& Kahneman, 1973, pp. 207-208). For our present purposes, then, when adolescents consider the probability that disaster will result from reckless behavior, they (implicitly) imagine a probability distribution. But when applied to themselves, the "essential feature" that is different is that it is "me" that is being considered, not some anonymous other. So even in situations where adolescents have an accurate understanding of the statistical probability of negative consequences resulting from reckless behavior, they may regard that distribution as being only very weakly representative of their own probability of suffering those consequences.

This kind of thinking is demonstrated most clearly in the research concerning sex without contraception. A perplexing finding in that area is that there is apparently little relationship between what adolescent girls know about fertility, conception, and contraception and whether or not they use contraception. Some studies do find a relationship between knowledge and use of contraception (Furstenberg, 1976; Oskamp \& Mindick, 1981), but to the puzzlement and dismay of those who would advocate early and comprehensive sex education for children, there simply is not a strong relationship between knowledge of contraception and the use of contraception; studies just as numerous find no relationship between them (Cvetkovich, Grote, Bjorseth, \& Sarkissian, 1975; Cvetkovich \& Grote, 1981; Gerrard, McCann, \& Fortini, 1983; Kane \& Lachenbruch, 1973). Representativeness makes sense of this paradox. Even when adolescents learn about the general probability of becoming pregnant, they may not consider their own fate to be strongly represented by that distribution.

The other heuristic described by Tversky and Kahneman is availability. Probability judgements are influenced by the ease with which relevant instances come to mind: "Classes whose instances are easy to construct or imagine will be perceived as more frequent than classes of the same size whose instances are less available" (Tversky \& Kahneman, 1973, p. 211). Tversky and Kahneman present a number of experiments supporting this idea. For example, subjects are asked to suppose that a word is selected at random. Is $\mathrm{K}$ more likely to be the first letter or the third letter of that word? Since words in which $\mathrm{K}$ is the first letter come to mind more 
easily than words in which $\mathrm{K}$ is the third letter, words with $\mathrm{K}$ as the first letter should be judged as more frequent, and indeed they are. With regard to reckless behavior, we might say that when an adolescent considers the likelihood that negative consequences will result from a reckless act, at that tender age occasions where negative consequences have indeed occurred are unlikely to be readily available. Simply knowing someone else who suffered negative consequences is unlikely to have much affect, because of adolescent egocentrism (although it may depend on the proximity of the relation). As with representativeness, the influence of a memory of a similar situation depends on the perceived similarity between the past situation and the current one. If the two are seen to be similar, then one might expect that what happened in the past will recur-but if the past situation involved someone else, it is unlikely that adolescents will perceive it as being sufficiently similar to a current situation involving "me."

In fact, for most adolescents the available precedents may even act to strengthen their conviction of exemption from disaster. The adolescent him/herself may in fact have driven a car while intoxicated, had sex without contraception, taken illegal drugs, or committed acts of delinquency many times without suffering for it. "Getting away with it" very likely bolsters and inflates whatever cognitive distortion existed to begin with. Winston Churchill observed that "nothing in life is so exhilarating as to be shot at without result." Most adolescents would, in their own way, heartily agree.

Studies supporting this model of the influence of cognitive factors on reckless behavior can be found in the areas of driving behavior, sex without contraception, and criminal behavior. In the area of automobile driving, it has been reported in several studies that adolescents take greater risks when driving and estimate their likelihood of getting into an accident, drunk or sober, as lower than their peers. Arnett (1990a) reported that high school-age males who have driven while drunk estimate the likelihood of an accident resulting from drunk driving as lower than do their peers who have not driven while drunk. Finn and Bragg (1986) found that younger drivers (18-24 years old) estimated their likelihood of getting into an accident as lower than that of their peers and lower than that of older drivers (38-50), in general and for a variety of specific driving situations, including driving after consuming six beers within $1 \mathrm{~h}$. Older drivers were less likely to show this tendency to rate themselves as superior to their peers. In a study by Matthews and Moran (1986), adolescent/young adult (18-25) and older adult (35-50) subjects were asked to make ratings of accident likelihood on a questionnaire of driving situations and after observing a variety of videotaped driving sequences. On both the questionnaire and the videotape ratings, the younger subjects 
consistently rated themselves as less likely to be involved in an accident in those situations than their peers, and also rated their ability to handle the situations in a manner similar to that of the older drivers. Again, older drivers did not exhibit as strongly biased a judgment of themselves in relation to their peers.

Concerning sex without contraception, a number of studies have provided evidence of the role of egocentrism and probability misjudgement. Kalmuss (1986) found that the perceived probability of becoming pregnant (from engaging in sexual activity without using birth control) is the strongest predictor of birth control use. Similarly, Gerrard et al. (1983) found that "ineffective" contraceptive users (those sexually active adolescent females who use unreliable contraception or none at all) are more likely than effective users to view their probability of becoming pregnant as low. Also, among the sexually active female adolescents studied by Oskamp and Mindick (1981), those who used contraception were less likely to believe that they could not get pregnant easily than those who did not use contraception. It should be noted, however, that in most research on sex without contraception, methodological problems call the results into question. Subjects typically have been drawn from girls who come to birth control clinics. Nevertheless, a study of a normal cross-section of high school-age females found this same pattern, with girls who had had sex without contraception estimating the likelihood of pregnancy resulting from that activity as lower than girls who had not (Arnett, 1990b).

Several studies of probability judgments in relation to crime also have implications in this area. A number of studies find that criminal behavior is inversely related to the perceived risk of formal sanctions (Erikson, Gibbs, \& Jensen, 1977; Grasmick \& Milligan, 1976; Jensen, Gibbs, \& Erikson, 1978), and it has also been found that the perceived probability that negative consequences will result from crime increases with age (Piliavin, Thornton, Gartner, \& Matsueda, 1986).

In summary, both theory and research suggest that cognitive factors play a role in reckless behavior among adolescents. Theoretically, the notion of adolescent egocentrism, and in particular the personal fable, provides a potential framework for understanding and describing the role of cognitive factors in reckless behavior. Also, the probability constructs of representativeness and availability presented by Tversky and Kahneman (1973) have strong implications for an understanding of reckless behavior. Research supports the assertion that cognitive factors are influential in reckless behavior. Furthermore, two studies on probability judgments related to driving and one on crime indicate that the gap between the probabilities one perceives for others for negative consequences from reckless behavior and the probabilities one perceives for oneself diminishes once the adolescent reaches adulthood. 
One study (Zuckerman, 1979b) has examined the interaction of sensation seeking and cognitive factors in risk taking, which might be considered to be a close cousin of reckless behavior. Sensation seeking had been found to be positively related to risk taking behavior such as participation in unusual psychological experiments and travel to unusual places, but it remained to be tested whether sensation seekers are more likely to take risks because they appraise risk differently or because the quality of the arousal produced by risk is experienced as pleasureable. The results of the study indicate that both factors are involved.

Zuckerman (1979b) notes that risk taking is influenced by the interaction of sensation seeking and anxiety. Confronted with a potentially risky situation, whether or not the person takes the risk depends on which is higher, the level of sensation seeking or the level of anxiety. Zuckerman found that people who are high in sensation seeking report less anxiety when faced with risks, both for risks involving participation in psychological experiments (taking an "unknown" drug) and for hypothetical travel-related risks. One reason for this, it was found, is that high sensation seekers tend to appraise novel situations as less risky than low sensation seekers do across a wide variety of risks. The operation of the personal fable is evident here in that the conviction that a negative outcome from taking a given risk "wouldn't happen to me" would lead naturally to a lower perception of risk, and a low perception of risk would in turn lead to a low level of anxiety. But even for situations where the high and low sensation seekers judged the level of risk equally, the high sensation seekers were less likely to respond with anxiety at the thought of entering the situation and more likely to anticipate that it would be enjoyable. High sensation seekers, then, not only appraise risk differently (i.e., lower), but they also anticipate risky situations with pleasure even (perhaps especially) when they acknowledge the risk involved.

\section{Peer Influences, Reinterpreted}

It has long been recognized that adolescence is the time of greatest susceptibility to peer influences (Berndt, 1979; Clasen \& Brown, 1985; Steinberg \& Silverberg, 1986). This seems to be especially true for transgressive (and sometimes reckless) behavior. Peer influences have been cited as a factor in the use of illegal drugs (Galambos \& Silbereisen, 1987; Halebsky, 1987; Meier, Burkett, \& Hickman, 1984), alcohol use (Dishion \& Loeber, 1985; McLaughlin, Baer, Burnside, \& Porkorny, 1985), sexual behavior (Collins \& Harper, 1985), cigarette smoking (Chasin, 1985; Hirschman, Leventhal, \& Glynn, 1984), and delinquency (Gomme, 1985). Some short-term longitudinal studies indicate that involvement with deviant peers precedes and leads to deviant behavior (Brook, Whitman, Gordon, \& Nomura, 1986; Hirschman et al., 1984), while others indicate that deviant adolescents seek each other out as friends because of the 
proclivity for deviant behavior they have in common (Galambos \& Silbereisen, 1987; Meier et al., 1984). Kandel (1985) reports on the basis of her longitudinal studies that adolescent friends tend to share characteristics such as drug use or nonuse before they become friends, but also that the likelihood of sharing this characteristic increases with the duration of the friendship.

In the context of sensation seeking and adolescent egocentrism, peer influences on reckless behavior might be interpreted in the following way. It can be expected that adolescents who share a high level of sensation seeking would be attracted to each other as friends on the basis of this similarity. In such a group of friends, the adolescent who is highest in sensation seeking might be likely to emerge as the leader of the group, especially with regard to reckless behavior. (Ozeran (1973) found that in groups, high sensation seekers tend to speak more and tend to be selected as group leaders.) Because high sensation is an inherent part of reckless behavior, the highest sensation seeker in the group would be most attracted to the prospect of engaging in reckless behavior. The rest of the group may go along with the highest sensation seeker on a reckless adventure, partly out of conformity and partly on behalf of their own sensation seeking propensities. For the followers, their sensation seeking propensities might not be high enough for them to initiate reckless behavior in most circumstances, but high enough for them to go allong once a leader initiates it.

Peer influences may also contribute to reckless behavior by mediating adolescent egocentrism in that the personal fable is likely to be strengthened when it is shared by a group of adolescents. Imagine, for example, a group of adolescents out drinking alcohol together. The evening comes to an end, and it is time to drive home. The driver for the group, however, realizes that he has had too much to drink and doubts his ability to drive them all home safely. His own personal fable comes to the rescue: "Oh, it'll be OK; nothing bad will happen." But it is also reinforced and inflated by his observations of his friends: clearly, they are not worried; none of them is mentioning any concern over the potential danger of driving in this condition. Perhaps each of them is thinking this on some level: "None of them seem to be worried; of course nothing bad will happen." The personal fable of each thus strengthened by their assumptions about the personal fables of their peers, or, one could say, by their participation in their collective fable, they proceed to drive home-and perhaps dodge the bullet, perhaps not.

\section{SENSATION SEEKING AND EGOCENTRISM IN THE CONTEXT OF A COMPREHENSIVE MODEL}

In the theory presented here, sensation seeking and adolescent egocentrism have been argued to be two influential factors promoting reckless 
behavior in adolescence. Both of these influences have been argued to arise developmentally in the sense that a predisposition toward a heightened level of both sensation seeking and egocentrism exists as a normal part of adolescent development.

However, sensation seeking and egocentrism are by no means the only factors involved in reckless behavior. Rather, they should be understood in the context of a comprehensive model which includes socialization influences. The socialization environment is crucial for how (and even whether) the developmental predispositions for sensation seeking and egocentrism are expressed, and socialization also directly influences participation in reckless behavior. If the socialization to which an adolescent is exposed is characterized by insistence on allegiance to the family and/ or community and adherence to group traditions, by clear expectations and responsibilities, and by a clearly and unambiguously communicated standard of conduct, with swift, certain, and forceful sanctions (verbal or physical) for any deviation from that standard-characterized, that is, by what will here be termed narrow socialization-then there is less allowance or tolerance for either predisposition to be expressed in its fullest form. If, in contrast, the socialization of the cultural environment promotes and encourages independence and autonomy, allows adolescents to determine right and wrong for themselves to a large extent, does not have a clearly articulated standard of conduct, and is inconsistent and lenient in enforcing such standard as there is-here termed broad socialization-then sensation seeking and egocentrism for those adolescents will be expressed more fully and will on average be higher. Adolescents' participation in reckless behavior will vary accordingly.

Narrow and broad socialization differ from terms that have been applied to socialization such as permissive/authoritarian/authoritative, laissez-faire/democratic/autocratic, in that they apply not just to parenting but to the entire ecological context of socialization (Bronfenbrenner, 1977), including neighborhood and community, institutions such as school and the legal system, the media (where existing), and ethnic, tribal, or national traditions: the whole culture. This conceptualization is perhaps especially appropriate for discussing socialization with regard to adolescents because by adolescence direct familial influences in socialization typically have diminished, while extrafamilial influences have risen in prominence (Emmerich, 1978; Floyd \& South, 1972; Sebald \& White, 1980).

In addition to affecting adolescent participation in reckless behavior through moderating sensation seeking and egocentrism, the narrowness or breadth of an adolescent's socialization affects the likelihood of reckless behavior in a number of direct ways within the ecological context. The family environment affects reckless behavior through family policies 
which impede or allow reckless behavior (Arnett, 1989), such as a nightly curfew, restrictions on automobile use, or requirements for performing family-related responsibilities. Communities affect reckless behavior through their sheer size (Mott \& Haupin, 1987); in a smaller community there may be more of a fear of social censure for reckless transgressions than in a larger community and perhaps more of a sense of responsibility to one's neighbors, since one knows many of them personally. The society as a whole also influences reckless behavior, through the media (including television, movies, popular music, and advertising), which provide models of indulgence or restraint (Bandura, 1973; Bandura \& Walters, 1963), and through laws and the legal system, which may (or may not) threaten and carry out punishment for reckless behavior.

The terms narrow and broad should be taken not as evaluative terms, in a positive or negative sense, but as terms indicating the amount of variance likely to exist among the adolescents in a given culture. For adolescents in a culture or family where socialization is narrow, a clear set of beliefs concerning good and bad, right and wrong, praiseworthy and unacceptable behavior is taught. There are clear expectations and responsibilities, and any deviation from the prescribed standard of conduct is strongly condemned and swiftly punished (physically or with disapproval and criticism). As a result, there is less deviance from this standard and less variance within the group. The range of individual predispositions for sensation seeking and egocentrism is pressed toward the low end of the distribution by this form of socialization, resulting in a narrower range and an overall lower level of these characteristics and of reckless behavior. (This is true within the community or culture; sensation seeking, egocentrism, and reckless behavior may still be allowed expression outward, toward enemies.) For adolescents in a culture or family where socialization is broad, it is left more to the individual to form principles of good and bad, right and wrong. There are fewer expectations and responsibilities, and there are fewer sanctions against deviating from such expectations and responsibilities as there are. Under this type of socialization, the variance among adolescents in their sensation seeking and egocentrism is likely to be great, as the entire range of individual predispositions is allowed to be expressed. The result is an overall higher level of reckless behavior. This has implications in three respects: between cultures, for a single culture over time, and within any given culture.

Between cultures, it can be expected that cultures with relatively narrow socialization will have adolescents who are less egocentric because they have been socialized strongly to contribute to and rely upon the family and/or the community. Also, they will have their propensities for sensation seeking directed outward (toward their enemies) or toward so- 
cially constructive ends, or even suppressed. In addition, adolescents in these cultures will have their behavior restricted directly by family, community, and society, through methods ranging from family rules to community censure to the legal system. As a consequence, the adolescents will engage in a lower rate of reckless behavior within the community. In contrast, adolescents in cultures with relatively broad socialization will be more egocentric on average because a primary concern with the self has not been discouraged or has even been encouraged, and their propensities for sensation seeking will be less socialized. There will also be fewer direct family, community, or societal restrictions on their behavior. As a consequence, they will engage in a higher rate of reckless behavior, i.e., behavior that holds the possibility of long-term adverse consequences to themselves and possibly to others within their community.

Narrow socialization is more likely to be characteristic of unindustrialized cultures, where communities are small and tightly integrated. One example of this can be found in the work of Herdt (1987) with the Sambia of New Guinea. Herdt describes a process of narrow socialization for male children beginning at age 7 , when they are taken away from their mothers and initiated into the male group, where they are prohibited from interaction with females until marriage. This initiation is the first of six stages of initiation, extending into young adulthood when the young man's first child is born. The initiations, especially in the early stages, involve thrashings, nose bleedings, and other painful and unpleasant surprises and humiliations. They also involve exhortations from the elders, concerning the necessity of maintaining the ritual practices, the prohibition against adultery, and the ideals of manhood for which they should strive. Children may resist but cannot avoid the initiations, at any stage. They are encouraged, coerced, and if necessary dragged into compliance.

As a consequence, there is very little reckless behavior among male Sambian adolescents, in the sense of behavior which is viewed as antisocial and disruptive by adults. The Sambia have no jails; none are needed. There is, however, one important avenue through which recklessness may be expressed: toward neighboring tribes. Significantly, it is part of the tradition at the close of the third stage of initiation for those who have just completed this initiation-the adolescents, 14 or 15 years old-to celebrate their new status by going together on a warring expedition. An adolescent who successfully kills an enemy during this expedition is lauded and viewed as having great promise. In later battles, adolescents may distinguish themselves by their recklessness, by displaying enjoyment of aggressive confrontations with other groups and a willingness to stand in the front lines of battle. Sensation seeking and egocentrism are evident here, but they have been socialized in such a way 
that they are not harmful to the group and may even be beneficial in defending it.

In another study, Whiting and Whiting (1975) compared children in six cultures which varied in cultural complexity (indicated by features such as occupational specialization, a cash economy, and a centralized politi$\mathrm{cal}$ and legal system) from simple to highly complex. They did not study adolescents, but what they found has implications for adolescence. They observed distinct differences in the kind of socialization that was characteristic of the different cultures. In particular, parents in what they termed simpler cultures were, in general, more strict with their children, requiring them to be responsible for important duties from an early age (such as child care of younger siblings, food preparation, and tending of livestock and fowl), and punishing disobedience swiftly and severely. As a consequence, their children were relatively dependable, responsible, and obedient compared to children in more complex cultures. Parents in what they termed complex cultures, in contrast, were generally more lenient with their children, more tolerant of disobedience, and required less work from them (because in a more complex society much of the simple and menial work around the home is done by automation). As a consequence, children in these cultures were observed to be relatively competitive and self-oriented, and less responsible and nurturant toward others.

It is plain how the idea of narrow and broad socialization applies to these findings. The narrow socialization of simpler societies results in less variance in the behavior of their children; because disobedience is closely monitored and swiftly and severely punished, and work on behalf of the group is required from an early age, there is less disobedience, less concern with the self, and more concern for others. In studying adolescence across cultures, it could be expected that a similar pattern would apply: narrow socialization, in simpler societies, results in lower levels of egocentrism and, consequently, less reckless behavior.

This is not meant to imply that narrow socialization is somehow superior or preferable to broad socialization. There may be trade-offs with both narrow and broad socialization. In the simpler societies described by the Whitings, characterized by narrow socialization, one reason children in these societies are able to contribute so much help to the family is that they do not attend school. In complex societies, the cost of providing universal education and encouraging competitiveness is a lesser concern for others and, it might be argued, greater egocentrism. Competition may prepare a child well for participation in a highly complex economy, but as the Whitings note, "competition for good grades is training for egoism and does not encourage a child to consider the needs of others" (Whiting \& Whiting, 1975, p. 107). 
It is possible that narrow socialization exacts a cost not only in lower education, but also in less creative and independent thinking; perhaps in cultures with narrow socialization, not only reckless behavior but also new ideas are inhibited and constrained because new ideas may challenge the tradition, the established order. This kind of analysis on a cultural level has yet to be performed, but within American culture adolescents in families which are strongly constraining and suppressive have been found to be inhibited, conventional, and less imaginative (Block, 1971; Schedler \& Block, 1990). Broad socialization, in highly technological societies, may result in a higher rate of reckless behavior but also in the kind of independent and creative thinking that leads to social and technological innovation. As Irwin (1990) and Zuckerman (1983) note, the willingness to take risks that is so strong among adolescents has great potential benefits as well as potential dangers. There is a cost to allowing this tendency too free a rein, in damage to the lives of adolescents and those around them, but there may also be a certain cost to constraining it tightly.

In addition to predicting differences in sensation seeking, egocentrism, and reckless behavior among adolescents of different cultures according to their narrow or broad socialization of adolescents, the theory presented here would also predict changes in these characteristics among adolescents in a single culture over time, as the narrowness or breadth of that culture's socialization changes. Recent trends in American society arguably provide one illustration. The past three decades have witnessed a dramatic and disquieting rise in the rate of reckless behavior among American adolescents. The rate of arrests for drunk driving among people aged 18-24 increased by almost $800 \%$ between 1965 and 1985 (U.S. Department of Education, 1988). Drug-related arrests for this age group increased by an appalling 1000\% during this same period. The rates of single motherhood and abortion have also increased steeply and steadily. From 1950 to 1981, the proportion of first-born children conceived out of wedlock among girls 15-19 rose from 18 to $60 \%$ (O'Connell \& Rogers, 1984), and from 1972 to 1983 the abortion rate for this group more than doubled (U.S. Department of Education, 1988). Crime and delinquency among adolescents have also risen markedly during this period. In 1950, the arrest rate for persons aged 14-24 was under 10 per 1000 persons; by 1985, it had risen to over 100 per 1000 persons (U.S. Department of Education, 1988). Simultaneously with the rise of these rates of reckless behavior, many observers have argued that this period has been marked by a growth in permissiveness among American parents and in American society generally (see Ehrenreich, 1989), including education, the media, and the legal system. This increasingly broad socialization may be one of the factors responsible for the rise in reckless behavior among adolescents. It should be noted, however, that these observations of increased 
permissiveness are largely unempirical; a more systematic sociocultural analysis awaits.

In any case, more telling than a post-hoc test of the theory would be to observe a culture currently in the process of changing its socialization of adolescents. Eastern Europe provides several such examples. The political changes taking place in those countries may result in socialization changes as well, most likely in the direction of broader socialization, with corresponding changes in sensation seeking, egocentrism, and reckless behavior among adolescents.

Although it may be useful to describe societies according to broad or narrow socialization, it is of course acknowledged that variance exists in every society, according to the practices of particular families. (Still, it might be noted that societies with narrow socialization are likely to be characterized by less variance among families because deviance from the norm by families will be censured as surely as deviance from the norm by adolescents. It should also be emphasized that, by adolescence, the family is only one influence among many in the milieu of socialization.) In families as in cultures, the model presented here would predict that adolescents who are subjected to narrow socialization will engage in relatively less reckless behavior, while adolescents whose families are characterized by broad socialization will engage in relatively more. To be specific, adolescents' sensation seeking, egocentrism, and reckless behavior will be in part predicted by the extent to which parents (1) share a certain clear set of beliefs about right and wrong and communicate these beliefs to their children, (2) expect their children to perform certain clearly specified duties for the family, duties which the parents communicate as important to the functioning of the family, and (3) enforce the rules and expectations based on these beliefs and duties consistently and forcefully.

Support for this prediction exists in research on the relationship between reckless behavior and parental beliefs, parental practices, and divorce. In a study of Jessor and Jessor (1977), parental beliefs were directly related to adolescents' reckless behavior in important ways. The authors defined a variable termed maternal ideology, which referred to mothers' beliefs about the social order, religion, and morality and was considered to reflect her socialization of her child. It was found that traditionalism/conventionality in maternal ideology, i.e., mothers' beliefs in the absoluteness of right and wrong, the importance of obeying the law, and the wrongness of socially disapproved behavior such as stealing, lying, drug use, and extramarital sex, was inversely related to her adolescent's participation in problem behavior. Conversely, lack of parental disapproval of problem behavior was associated with relatively greater participation in it. From the perspective of the present theory, it is argued 
that this demonstrates the influence of narrow and broad socialization on adolescents' reckless behavior.

Other research on parenting also supports the model, indicating that a lack of involvement and monitoring by parents is related to recklessness among adolescents. Block (1971; Schedler \& Block, 1990), in a longitudinal study following individuals from early adolescence to their 30 's, reported that adolescents whose parents were characterized as uninvolved and neglecting were significantly more undercontrolled and impulsive than other adolescents. Although attitudes and personality characteristics, not behavior, were the focus of this study, it might reasonably be argued that the characteristics of being undercontrolled and impulsive would lead to reckless behavior. A longitudinal study in Finland (Pulkinnen, 1982) produced comparable results: low parental involvement in childhood was predictive of deviant behavior in early adolescence, in particular truancy, alcohol consumption, and smoking. Also Patterson (1982), from extensive work with delinquent adolescents, connects a lack of parental monitoring of children to adolescent delinquent behavior such as stealing and social aggressiveness. This pattern of association between parental fecklessness or neglect and adolescent delinquency/reckless behavior has been found consistently over several decades (Glueck \& Glueck, 1950; Hirschi, 1969; Levine \& Kozak, 1979; McCord \& McCord, 1959). The present theory would predict that sensation seeking and egocentism would be found to be two of the mediating variables between uninvolved parenting and reckless behavior. Parenting that is uninvolved and that fails to provide limits, sanctions, and a moral structure does not socialize the developmental propensities for sensation seeking and egocentrism, which may be expressed as reckless behavior.

One might expect broader socialization in divorced families than in nondivorced families because the multiple burdens-financial, occupational, emotional-which fall upon the custodial parent would make it more difficult to summon the time and energy necessary for narrow socialization. This expectation is supported in research on reckless behavior, where parents' divorce has been found to be related to drug use (Johnson et al., 1984), sexual behavior (Eberhardt \& Schill, 1984), and delinquency (Stumphauser, 1976). It might be argued that reckless behavior in the aftermath of divorce could be an externalization of adolescents' unhappiness and confusion surrounding divorce, except that for adolescents in divorced families it is probable that the divorce took place many years ago in most cases (although age of child at divorce is a variable rarely considered in research on adolescence). Still, it should be noted that there is likely to be a great deal of variance in divorced families. In some divorced families, the duties and expectations for the children may increase, and also the closeness of the children to their custodial parent 
(Weiss, 1979), resulting in effect in narrower socialization and less reckless behavior. These variations, and whether sensation seeking and egocentrism mediate their connections to reckless behavior, remain to be studied.

\section{COMPARISON TO JESSOR AND JESSOR'S PROBLEM BEHAVIOR THEORY}

Jessor and Jessor (1977; Jessor, 1987a,b; Jessor, 1990) have presented the most fully articulated theory of reckless behavior (or, as they term it, problem behavior) in adolescence. Many factors are included in their model (see Jessor, 1987a), but the developmental basis of the theory is that adolescents engage in problem behavior more than other age groups primarily because it serves as a mark of adult status (Jessor, 1987a, p. 339). Certain behavior in our society, such as alcohol consumption and sexual activity, is socially approved for adults but not adolescents, according to the legal and/or moral standards of society. Adolescents violate the prohibitions and engage in the prohibited behavior because it signifies the adult status they wish to attain. Problem behavior diminishes after adolescence because it is no longer necessary as a declaration of adulthood.

They tested this theory in a large scale longitudinal study of high school and college students, examining a wide variety of personality and social environment variables in relation to five types of problem behavior: sexual activity, drinking, problem drinking (which concerned not behavior per se but the experience of negative consequences as a result of excessive drinking), marijuana use, and general deviance (including lying, stealing, and vandalism). The study was among the first to consider a number of these kinds of behavior together, as a syndrome, rather than in isolation and remains an important empirical contribution to the area. The model presented in the theory contains elements such as parental control and parental ideology which are important to recognize and which have been applied to the present theory as part of the ideas of broad and narrow socialization.

However, both the design and the results refute the developmental theory that underlies the study. They argue that the desire to achieve a more adult status is "the developmental role played by the initiation of problem behavior during adolescence" (Jessor, 1987a, p. 339). A case could perhaps be made that adolescents wish to engage in sexual activity and alcohol consumption partly because these are activities that are approved for adults and proscribed for adolescents, and adolescents desire to signify their attainment of adulthood. Lying, stealing, and vandalism, however, which are also part of the syndrome of problem behavior they have identified, are no more socially acceptable for adults than for ado- 
lescents; marijuana use is arguably even less socially acceptable behavior for adults than for adolescents. Including marijuana use and general deviance in the design along with sexual activity and alcohol use is an implicit recognition that developmental factors other than the pursuit of adult status are involved.

The results of the study also contradict the theoretical model. If problem behavior theory were accurate, it might have been expected that behavior prohibited for adolescents but approved for adults (sexual activity and moderate drinking) would have been found to be unrelated to behavior prohibited at any age (marijuana use, general deviance). In fact, however, the various kinds of problem behavior were found to be highly correlated. This is more consistent with the model presented here, in which it is argued that a wide variety of forms of reckless behavior sprout from the common developmental soil of sensation seeking and egocentrism.

It should be added that, although the Jessors' theory proposes the desire to achieve adult status as the developmental basis for the prevalence of problem behavior in adolescence, neither their original study nor subsequent studies have included measurements or evaluations of the presence of this characteristic.

The theories also differ in what they would predict concerning the prevalence among adolescents of problem/reckless behavior in areas where adolescents are allowed access to activities that signify adulthood but which are also potentially reckless. It might be predicted from Jessor and Jessor's theory that the prevalence of problem behavior would be low for adult-like behavior in which adolescents are allowed to participate. The present theory, in contrast, would predict that adolescents will be most reckless in the areas where they are given the most unsocialized and unmonitored opportunity to be reckless-in the areas which are least, rather than most, restricted to them.

Perhaps the best test of this contrast in predictions is in the area of automobile driving. Driving is age-graded in the U.S., but the age of entry into socially approved driving is earlier (16 in most states) than that for other kinds of age-graded behavior (for example, the legal drinking age is 21 in most states). It might be expected on the basis of problem behavior theory, then, that the rate of problem behavior associated with driving would be low. In fact, however, just the opposite is true. Driving-related reckless behavior is a pervasive form of reckless behavior among adolescents (U.S. Department of Education, 1988). This is true long past the age of 16, when adolescents are first allowed to drive; adolescents 20-24 also have significantly higher rates of accidents and fatalities than older age groups (U.S. Bureau of the Census, 1987). Even adolescents who do not 
behave recklessly in other ways tend to drive at high speeds (Arnett, 1990c). This is consistent with what would be predicted by the present theory.

\section{THE DECLINE OF RECKLESS BEHAVIOR}

How and why does reckless behavior finally diminish? Thus far, few studies have examined the decline of reckless behavior as adolescents enter adulthood. However, there are a number of theoretical and empirical suggestions that point the way for future research.

Elkind (1967) suggests that the personal fable is overcome by the entrance into Erikson's (1963) intimacy stage: in the course of establishing a long-term intimate relationship (typically, marriage) with another person, we discover that others have similar feelings and describe similar agonies and raptures. This discovery punctures the belief that our own experiences are unique and unparalleled. It might also be added that marriage diminishes the likelihood of reckless behavior in a number of specific ways. For example, sex without contraception no longer has connotations of recklessness once the person is married, and most people are married by their late 20 's. Also, marriage, with its attendant responsibilities and restrictions, probably contributes to a decline in reckless driving, crime, and drug use as well. Statistically, it is true that young married adults have a lower rate of driving offenses and crime than young unmarried adults (U.S. Bureau of the Census, 1987).

Another reason reckless behavior declines with age may be that the biological "engine" that drives it slows downs. Biological measures associated with sensation seeking (AEP, sex hormone levels) show a pattern in relation to age that reflects a decline in energy and intensity; the decline in relation to sensation seeking may also underlie a decline in relation to reckless behavior. Zuckerman et al. (1978) observe: "What is the basis of the increasing cautiousness and conservatism of age? It might simply reflect the mellowing effect of accumulated experience. But many biological changes also occur with age, including a slowing of cortical activity and a diminution of gonadal output ... It can be hypothesized that the same biological factors that are prominent in aging effect the sensation seeking tendency' (p. 148). This, however, remains to be tested directly.

Piaget cites the importance of work experience for attenuating adolescent egocentrism. Work requires the individual to bend his/her ideal vision of things to fit the real: "In other words, the job leads thinking away from the dangers of formalism back to reality" (Inhelder \& Piaget, 1958, p. 346). Steinberg, Greenberger, Jacobi, and Garduque (1981) also suggest that work experience leads to the decline of adolescent egocentrism and 
support that contention with interviews with high school students who have part-time jobs. However, several studies (Bachman, Johnston, \& O'Malley, 1982; Ruggiero, Greenberger, \& Steinberg, 1982; Shannon, 1982) have found that working may actually promote reckless behavior by providing adolescents with the money to engage in it, by creating stress that adolescents may ameliorate through substance use, and by providing an additional venue for stealing money and property. If work does attenuate reckless behavior, it may be only in a job that is viewed as a potential step to a career, so that the adolescent is highly motivated to avoid reckless behavior that might jeopardize it.

Tversky and Kahneman's (1973) notion of availability also applies to the decline of reckless behavior. As adolescents grow older, into the late 20 's and early 30's, the cumulative likelihood of suffering the consequences of reckless behavior rises. Somewhere in the course of years of reckless behavior, adolescents may get a ticket for driving wildly or under the influence of alcohol or may have a serious automobile accident; they may be involved in an unintentional pregnancy; they may have a bad experience with drugs; they may have an embarassing or careerthreatening experience with the law. It is probably not necessary to suffer disaster in order to develop out of adolescent egocentrism, but in many cases it may be sufficient. Thus far, no studies have examined the influence of negative experiences on reckless behavior through adolescence to young adulthood.

Finally, reckless behavior may decrease with age among populations partly because some of the most reckless members of any cohort will die young. Extreme recklessness is not a good prescription for survival. By midlife, a fatal automobile accident, a violent death related to crime, or an accidental death resulting from some other variant of reckless behavior has claimed a substantial number of those who exhibited an especially high level of reckless behavior in adolescence. Current data charting the decline of reckless behavior with age are mostly cross-sectional; more longitudinal studies are needed.

\section{CONCLUSION}

Reckless behavior in adolescence is manifested in our time in driving at high speeds and while drunk, sex without contraception, illegal drug use, delinquency and crime, and countless other less common varieties. Sensation seeking and adolescent egocentrism are normative developmental features of adolescence that are implicated in the high level of reckless behavior during that age period. Considerable research evidence supports the relation between these factors and the various prominent forms of reckless behavior in adolescence. The narrowness or breadth of an adolescent's socialization environment is also an important factor in reckless 
behavior, directly and in interaction with the developmental factors of sensation seeking and egocentrism. One of the clearest findings in the area is that reckless behavior does decline after adolescence. Why this is true remains to be established, although it is probable that the biologically based decline in sensation seeking, increasing cognitive maturity, and the assumption of greater personal and occupational responsibilities are involved.

\section{REFERENCES}

Amett, J. (1989, April). Understanding reckless behavior in adolescence. Paper presented at the biennial meeting of the Society of Research in Child Development, Kansas City.

Amett, J. (1990a). Drunk driving sensation seeking, and egocentrism among adolescents. Personality and Individual Differences, 11, 541-546.

Amett, J. (1990b). Contraceptive use, sensation seeking and adolescent egocentrism. Journal of Youth of Adolescence, 19, 171-180.

Arnett, J. (1990c). The development of reckless behavior in adolescence, ages 15-18. Unpublished data.

Amett, J. (1992, April). Sensation seeking and adolescent reckless behavior: A new conceptualization and a new scale. Poster presented at the biennial meeting of the Society for Research on Adolescence, Washington, D.C.

Bachman, J., Johnston, L., \& O'Malley, P. (1982). Smoking, drinking and drug use among American high school students. American Journal of Public Health, 71, 59-69.

Bandura, A. (1973). Aggression: A social learning analysis. Englewood Cliffs, NJ: PrenticeHall.

Bandura, A., \& Walters, R. H. (1963). Social learning and personality development. New York: Holt, Rinehart \& Winston.

Beirness, D. J., Haas, G. C., Walsh, P. J., \& Donelson, A. C. (1985). Alcohol and fatal road accidents in Canada: A statistical look at its magnitude and persistence. Ottawa, Ontario, Canada: Department of Justice.

Berndt, T. J. (1979). Developmental changes in conformity to peers. Developmental Psychology, 15, 608-616.

Blackburn, R. (1978). Psychopathy, arousal, and the need for stimulation. In R. D. Hare and D. Schalling (Eds.), Psychopathic behavior. New York: Wiley.

Block, J. (1971). Lives through time. Berkeley, CA: Bancroft.

Brill, H. Q., \& Christie, R. L. (1974). Marijuana use and psychosocial adaptation: Followup study of a collegiate population. Archives of General Psychiatry, 31, 713-719.

Bronfenbrenner, U. (1977). Ecological factors in human development in retrospect and prospect. In H. McGurk (Ed.), Ecological factors in human development. Amsterdam: North-Holland.

Brook, J., Whiteman, M., Gordon, A., \& Nomura, C. (1986). Onset of adolescent drinking: A longitudinal study of intrapersonal and interpersonal antecedents. Advances in Alcohol and Substance Abuse, 5, 91-110.

Buchsbaum, M. S. (1971). Neural events and the psychophysical law. Science, 172, 502.

Buchsbaum, M. S. (1974). Average evoked response and stimulus intensity in identical and fraternal twins. Physiological Psychology, 2, 365-370.

Chassin, L. (1985). Changes in peer and parent influence during adolescence: Longitudinal versus cross-sectional perspectives on smoking initiation. Developmental Psychology, 22, 327-334.

Clark, W. B., \& Midanik, L. (1980). Alcohol use and alcohol problems among U.S. adults: 
Results of the 1979 National Survey (Working Paper F122). Berkeley, CA: Alcohol Research Group.

Clasen, D., \& Brown, B. (1985). The multidimensionality of peer pressure in adolescence. Journal of Youth and Adolescence, 14, 45I-468.

Collins, J. K., \& Harper, J. F. (1985). Sexual behavior and peer pressure in adolescent girls. Australian Journal of Sex, Marriage, and Family, 6, 137-142.

Coursey, R. D., Buchsbaum, M., \& Frankel, B. L. (1975). Personality measures and evoked responses from chronic insomnias. Journal of Abnormal Psychology, 84, 239249.

Cretkovich, G., \& Grote, B. (1981). Adolescent development and teenage fertility. In D. Byrne \& W. A. Fisher (Eds.), Adolescents, sex, and contraception (109-123). New York: McGraw-Hill.

Cvetkovich, G., Grote, B., Bjorseth, A., \& Sarkissian, J. (1975). On the psychology of adolescents' use of contraceptives. Journal of Sex Research, 11, 256-270.

Daitzman, R. J., \& Zuckerman, M. (1980). Disinhibitory sensation seeking personality, and gonadal hormones. Personality and Individual Differences, 1, 103-110.

Daitzman, R. J., Zuckerman, M., Sammelwitz, P. H., \& Ganjam, V. (1978). Sensation seeking and gonadal hormones. Journal of Bioscience, 10, 40I-408.

Davis, G. L., \& Cross, H. J. (1973). College student drug users' memories of their parents. Adolescence, 7, 475-480.

Dembo, R. L., Dertke, M., laVoie, L., \& Bonders, S. (1987). Physical abuse, sexual victimization, and illicit drug use: A structural analysis among high risk adolescents. Journal of Adolescence, 10, 13-34.

Dishion, T. J., \& Loeber, R. (1985). Adolescent marijuana and alcohol use: The role of parents and peers revisited. American Journal of Drug and Alcohol Abuse, 11, II-25.

Donovan, J. E., Jessor, R., \& Costa, F. M. (1988). Syndrome of problem behavior in adolescence: A replication. Journal of Consulting and Clinical Psychology, 56, 762-765.

Eberhardt, C. A., \& Schill, T. (1984). Differences in sexual attitudes and likelihood of sexual behaviors of black lower socioeconomic father-present vs. father-absent female adolescents. Adolescence, 19, 99-105.

Ehrenreich, B. (1989). Fear of falling: The inner life of the middle class. New York: Pan theon.

Elkind, D. (1967). Egocentrism in adolescence. Child Development, 38, 1025-1034.

Elkind, D. (1968). Cognitive structure and adolescent experience. Adolescence, 2, 427-434.

Elkind, D. (1985). Egocentrism redux. Developmental Review, 5, 218-226.

Elster, A. B., Lamb, M. E., \& Tavare, J. (1987). Association between behavioral and school problems and fatherhood in a national sample of adolescent youths. Journal of Pediatrics, 111, 932-936.

Elster, A. B., Ketterlinus, R., \& Lamb, M. E. (1989). The association between parental status and problem behavior among female adolescents. Paper presented at the biennial meeting of the Society for Research in Child Development, Kansas City, April.

Emmerich, H. J. (1978). The influences of parents and peers on choices made by adolescents. Journal of Youth and Adolescence, 7, 175-180.

Emmons, T. D., \& Webb, W. W. (1974). Subjective correlates of emotional responsivity and stimulation seeking in psychopaths, normals, and acting-out neurotics. Journal of Consulting and Clinical Psychology, 42, 620-625.

Erikson, E. (1963). Childhood and society. New York: Norton.

Erikson, M., Gibbs, J. P., \& Jensen, G. F. (1977). The deterence doctrine and the perceived certainty of legal punishments. American Sociological Review. 42, 305-317.

Farley, F. H. (1973). A theory of delinquency. Paper presented at the annual meeting of the American Psychological Association, Montreal, Quebec. 
Farley, F. H., \& Farley, S. V. (1972). Stimulus-seeking motivation and delinquent behavior among institutionalized delinquent girls. Journal of Consulting and Clinical Psychology, $39,94-97$.

Farrington, D. P. (1989). Self-reported and official offending from adolescence to adulthood. In M. W. Klein (Ed.), Cross-national research in self-reporled crime and delinquency. Boston: Kluwer.

Finn, P., \& Bragg, B. W. (1986). Perception of risk of an accident by young and older drivers. Accident Analysis and Prevention, 18, 289-298.

Fishburne, P. M., Abelson, H. I., \& Cisin, I. (1980). National survey on drug abuse: main finding: 1979. Rockville, MD: National Institute of Drug Abuse.

Flavell, J. (1985). Cognitive development. Englewood Cliffs, NJ: Prentice-Hall.

Floyd, H. H., Jr., \& South, D. R. (1972). Dilemma of youth: The choice of parents or peers as a frame of reference for behavior. Journal of Marriage and the Family, 34, 627-634.

Furstenburg, F. (1976). Unplanned parenthood. New York: Free Press.

Galambos, N. L., \& Silbereisen, R. K. (1987). Substance use in West German youth: A longitudinal study of adolescents" use of alcohol and tobacco. Journal of Adolescent Research, 2, 161-174.

Gans, J., Blyth, D., Elster, A., \& Gaveras, L. L. (1990). America's adolescents: How healthy are they? (Vol. 1). Chicago: American Medical Association.

Gerrard, M., McCann, L., \& Fortini, M. (1983). Prevention of unwanted pregnancy. American Journal of Community Psychology, 11, 153-167.

Glueck, S., \& Glueck, E. (1950). Unravelling juvenile delinquency. New York: Commonwealth Fund.

Goldsmith, S., Gabrielson, M. O., Gabrielson, I., Mathews, V., \& Potts, L. (1972). Teenagers, sex, and contraception. Family Planning Perspectives, 4, 32-38.

Goldstein, L. G., \& Mosel, J. N. (1958). A factor study of drivers' attitudes with further study on driver aggression. Highway Research Board Bulletin, 172, 9-29.

Gomme, I. M. (1985). Predictors of status and criminal offenses among male and female adolescents in an Ontario community. Canadian Journal of Criminology, 27, 147-159.

Grasmick, H. G., \& Milligan, H. M. Jr. (1976). Deterrence theory approach to socioeconomic/demographic correlates of crime. Social Science Quarterly, 57, 608-617.

Halebsky, M. (1987). Adolescent alcohol and substance abuse: Parent and peer effects. Adolescence, 22, 961-967.

Hansson, R. O., O'Connor, M. E., Jones, W. H., \& Blocker, T. J. (1981). Maternal employment and adolescent sexual behavior. Journal of Youth and Adolescence, 101, 55-60.

Harman, S. M. (1978). Clinical aspects of aging of the male reproductive system. In E. L. Schneider (Ed.), The aging reproduclive syslem (Aging, Vol. 4). New York: Raven Press.

Herdt, G. (1987). The Sambia: Ritual and gender in New Guinea. New York: Holt, Rinehart \& Winston.

Hirschi, T. (1969). Causes of delinquency. Berkeley: Univ. of California Press.

Hirschman, R. S., Leventhal, H., \& Glynn, K. (1984). The development of smoking behavior: Conceptualization and supportive cross-sectional survey data. Journal of Applied Social Psychology, 14, 184-206.

Hundleby, J. D. (1987). Adolescent drug use in a behavioral matrix: A confirmation and comparison of the sexes. Addictive Behaviors, 12, 103-112.

Inhelder, B., \& Piaget, J. (1958). The growth of logical thinking from childhood to adolescence. New York: Basic Books.

Irwin, C. E. (1990). The theoretical concept of at-risk adolescents. Adolescent Medicine, 1, $1-14$. 
Jensen, G. F., Gibbs, J. P., \& Erikson, M. (1978). Perceived risk of punishment and selfreported delinquency. Social Forces, 57, 57-78.

Jessor, R. (1987a). Problem behavior theory, psychosocial development, and adolescent problem drinking. British Journal of Addiction, 82, 331-342.

Jessor, R. (1987b). Risky driving and adolescent problem behavior: An extension of problem behavior theory. Alcohol, Drugs, and Driving, 3, 1-11.

Jessor, R. (1990). Road safety and health behavior: Some lessons for research and intervention. Health Education Research, 5, 1-3.

Jessor, R., \& Jessor, S. L. (1977). Problem behavior and psychosocial development: A longitudinal study of youth. New York: Academic Press.

Jonah, B. A. (1984). Accident risk and risk-taking among young drivers. Paper presented at the Conference on Risk-Taking in Adolescent Drivers, University of British Columbia, Vancouver.

Jonah, B. A. (1986). Accident risk and risk-taking behaviour among young drivers. Accident Analysis and Prevention. 18, 255-271.

Jonah, B. A., \& Wilson, R. J. (1984). Drinking and driving among youth. Paper presented at the Workshop on Epidemiological and Social Psychological Studies in Alcohol and Drug Use Among Youth, Toronto.

Johnson, G. M., Shontz, F. C., \& Locke, T. P. (1984). Relationships between adolescent drug use and parental drug behavior. Adolescence, 19, 295-299.

Kahneman, D., \& Tversky, A. (1972). Subjective probability: A judgement of representativeness. Cognitive Psychology, 3, 430-454.

Kalmuss, D. (1986). Contraceptive use: A comparison of ever- and never-pregnant adolescents. Journal of Adolescent Healih Care, 7, 332-337.

Kandel, D. (1985). On processes of peer influences in adolescent drug use: A developmental perspective. Advances in Alcohol and Substance Abuse, 139-163.

Kane, F. J., Jr., \& Lachenbruch, P. (1973). Adolescent pregnancy: A study of aborters and non-aborters. American Journal of Orhopsychiatry, 43, 796-803.

Keating, D. (1980). Thinking processes in adolescence. In J. Adelson (Ed.), Handbook of adolescent psychology. New York: Wiley.

von Knorring, L., Oreland, L., \& Winblad, B. (1983). Personality traits related to monoamine oxidase (MAO) activity in platelets. Submitted for publication.

Kuhn, D., Phelps, E., \& Walter, J. (1985). Correlational reasoning in an everyday context. Journal of Applied Developmental Psychology, 6, 85-97.

Levine, E. M., \& Kozak, C. (1979). Drug and alcohol use, delinquency, and vandalism among upper middle class pre- and post-adolescents. Journal of Yourh and Adolescence, $8,91-101$.

Levine, M., \& Singer, S. (1988). Delinquency, substance abuse, and risk-taking in middleclass adolescents. Behavioral Sciences and the Law, 6, 385-400.

Lukas, J. H., \& Siegel, J. ([981). Human augmenting-reducing and sensation-seeking. Paper presented at meeting of the Society for Psychophysiological Research. Washington, DC, October.

Major, L. F., \& Murphy, D. L. (1978). Platelet and plasma amine oxidase activity in alcoholic individuals. British Journal of Psychiatry, 132, 548-554.

Matthews, M., \& Moran, A. (1986). Age differences in male drivers' perception of accident risk: The role of perceived driving ability. Accident Analysis and Prevention, 18, 299 313.

McCord, W., \& McCord, J. (1959). Origins of crime. New York: Columbia Univ. Press.

McLaughlin, R. J., Baer, P. E., Burnside, M. A., \& Pokorny, A. D. (1985). Psychosocial correlates of alcohol use at two age levels during adolescence. Journal of Studies on Alcohol, 46, 212-210. 
Meier, R. F., Burkett, S. R., \& Hickman, C. A. (1984). Sanctions, peers, and deviance: Preliminary models of a social control process. Sociological Quarterly, 25, 67-82.

Moshman, D. (1979). Development of formal hypothesis-testing ability. Developmental Psychology, 15, 104-112.

Mott, F. L., \& Haurin, R. J. (1987). The interrelateness of age at first intercourse, early' pregnancy, alcohol, and drug use among American adolescents: Preliminary results from the National Longitudinal Survey of Youth Labor Market Experience. Columbus, $\mathrm{OH}$ : Center for Human Resource Research, Ohio State University.

Murphy, D. J. (1986). Custorners and theives: An ethnography of shoplifting. Dorset, England: Gower.

Murphy, D. L., Belmaker, R. H., Buchsbaum, M., Wyatt, R. J., Martin, N. F., \& Ciaranello, R. (1977). Biogenic amine-related enzymes and personality variations in normals. Psychological Medicine, 7, 149-157.

Murphy, D. L., Wright, C., Buchsbaum, M. S., Nichols, A., Costa, J. L., \& Wyatt, R. J. (1976). Platelet and plasma amine oxidase activity in 680 normals: Sex and age differences and stability over time. Biochemical Medicine, 16, 254-265.

O'Connell, M., \& Rogers, C. C. (1984). Out-of-wedlock births, premarital pregnancies, and their effect on family formation and dissolution. Family Planning Perspectives, 16, 157-162.

Oskamp, S., \& Mindick, B. (1981). Personality and attitudinal barriers to contraception. In D. Byrne \& W. A. Fisher (Eds.), Adolescents, sex, and contraception (pp. 65-107). New York: McGraw-Hill.

Ozeran, B. J. (1973). Sensation seeking as a predictor of leadership in leaderless, taskoriented groups. Master's thesis, University of Hawaii.

Patterson, G. (1982). Coercive family process. Eugene, OR: Castalia.

Perez, J., \& Torrubia, R. (1985). Sensation seeking and antisocial behavior'in a student sample. Personality and Individual Differences, 6, 401-403.

Piaget, J. (1967). Six psychological studies. New York: Random House.

Piaget, J., \& Inhelder, B. (1975). The origin of the idea of chance in children. New York: Norton.

Piliavin, 1., Thornton, C., Gartner, R., \& Matsueda, R. L. (1986). Crime, deterrence, and rational choice. American Sociological Review, 51, 101-119.

Pulkinnen, L. (1982). Self-control and continuity from childhood to adolescence. In P. B. Baltes \& O. G. Brim (Eds.), Lifespan development and behavior (Vol. 4). New York: Academic Press.

Robinson, D. S., Davis, J. M., Nies, A., Ravaris, C. L., \& Sylvester, D. (1971). Relation of sex and aging to monoamine oxidase activity of human brain, plasma, and platelets. Archives of General Psychiatry, 24, 536-539.

Rose, R. M. (1978). Neuroendocrine correlates of sexual and aggressive behavior in humans. In M. A. Lipton, A. Dimascio, \& K. F. Killam (Eds.), Psychopharmacology: A generation of progress. New York: Raven Press.

Ross, B. M., \& DeGroot, J. F. (1982). How adolescents combine probabilities. Journal of Psychology, 110, 75-90.

Rowe, A. R., \& Tittle, C. R. (1977). Life cycle changes and criminal propensity. Sociological Quarterly, 18, 223-236.

Ruggiero, M., Greenberger, E., \& Steinberg, L. (1982). Occupational deviance among firsttime workers. Youth and Society, 13, 423-48.

Satinder, K. P., \& Black, A. (1984). Cannibis use and sensation seeking orientation. Journal of Psychology, 116, 101-105.

Schwarz, R. M., Burkhart, B. R., \& Green, B. (1978). Turning on or turning off: Sensation 
seeking or tension reduction as motivational determinants of alcohol use. Journal of Consulting and Clinical Psychology, 46, 1144-1145.

Schooler, C., Zahn, T. P., Murphy, D. L., \& Buchsbaum, M. (1978). Psychological correlates of monoamine oxidase activity in normals. Journal of Nervous and Mental Diseases, $166,177-186$.

Sebald, H., \& White, B. (1980). Teenagers' divided reference groups: Uneven alignment with parents and peers. Adolescence, 15, 979-984.

Shannon, L. W. (1982). Assessing the relationship of adult criminal activity to juvenile careers. Washington, DC: U.S. Department of Justice. [Microfiche No. NCJ 77744, available from the National Juvenile Justice Clearinghouse of the National Criminal Justice Reference Service, Washington, DCl

Shedler, J., \& Block, J. (1990). Adolescent drug use and psychological health: A longitudinal inquiry. American Psychologist, 45, 612-630.

Silverman, J., Buchsbaum, M. S., \& Stierlin, H. (1973). Sex differences in perceptual differentiation and stimulus intensity control. Journal of Personality and Social Psychology, 25, 309-318.

Spotts, J. V., \& Shontz, F. C. (1984). Correlates of sensation seeking by heavy, chronic drug users. Perceptual and Motor Skills, 58, 427-435.

Steinberg, L. D., Greenberger, E., Jacobi, M., \& Garduque, L. (1981). Early work experience: A partial antidote for adolescent egocentrism. Journal of Youth and Adolescence, 10, 141-157.

Steinberg, L., \& Silverberg, S. B. (1986). The vicissitudes of autonomy in early adolescence. Child Development, 57, 841-851.

Stern, M., Northmn, J. E., \& Van Slyck, M. R. (1984). Father absence and adolescent 'problem behaviors': Alcohol consumption, drug use, and sexual activity. Adolescence. $19,301-312$.

Stillman, R. C., Wyatt, R. J., Murphy, D. L., \& Rauscher, F. D. (1978). Low platelet monoamine oxidase activity and chronic marijuana use. Life Sciences, 23, 1577-1582.

Stumphauser, J. S. (1976). Modifying delinquent behavior: Beginnings and current practices. Adolescence, 11, 13-28.

Sutker, P. B., Archer, R. P., \& Allain, A. N. (1978). Drug abuse patterns, personality characteristics, and relationships with sex, race, and sensation seeking. Journal of Consulting and Clinical Psychology, 46, 1374-1378.

Tietze, C. (1983). Induced abortion: A world review. New York: The Population Council, Inc.

Tversky, A., \& Kahneman, D. (1973). Availability: A heuristic for judging frequency and probability. Cognitive Psychology, 5, 207-232.

U.S. Bureau of the Census (1987). Statistical abstracts of the United States (108th ed.). Washington, DC.

U.S. Department of Education (1988). Youth indicators 1988: Trends in the well-being of American youth (DE Publication No. 065-000-00347-3). Washington, DC: U.S. Government Printing Office.

Wavering, M. (1984). Interrelationships among Piaget's formal operational schemata: Proportions, probability, and correlation. Journal of Psychology, 118, 57-64.

Weiss, R. S. (1979). Growing up a little faster: The experience of growing up in a singleparent household. Journal of Social Issues, 35, 97-111.

Whiting, B. B., \& Whiting, J. W. M. (1975). Children of six cultures: A psychocultural analysis. Cambridge, MA: Harvard Univ. Press.

Williams, A. F. (1985). Night-time driving and fatal crash involvement of teenagers. Accident Analysis and Prevention, 17, 1-5. 
Wilson, J. Q. \& Herrnstein, R. J. (1985). Crime and human nature. New York: Simon \& Schuster.

Yamaguchi, K., \& Kandel, D. (1987). Drug use and other determinants of premarital pregnancy and its outcome: A dynamic analysis of competing life events. Journal of Marriage and Family, 49, 257-270.

Zelnik, M.. \& Kantner, J. P. (1980). Sexual activity, contraceptive use, and pregnancy among metropolitan-area teenagers, 1971-1979. Family Planning Perspectives. 12, 230.

Zuckerman, M. (1979a). Sensation seeking: Beyond the optimal level of arousal. Hillsdale, NJ: Erlbaum.

Zuckerman, M. (1979b). Sensation seeking and risk taking. In C. E. Izard (Ed.), Emotions in personality and psychopathology. New York: Plenum.

Zuckerman, M. (1983). A biological theory of sensation seeking. In M. Zuckerman (Ed.), Biological bases of sensation seeking, impulsivity, and anxiety. Hillsdale, NJ: Erlbaum.

Zuckerman, M. (1984). Sensation seeking: A comparative approach to a human trait. Behavioral and Brain Sciences. 7, 413-471.

Zuckerman, M., Bone, R. N., Neary, R., Mangelsdorff, D., \& Brusıman, B. (1972). What is the sensation seeker? Personality trait and experience correlates of the Sensation Seeking Scales. Journal of Consulting and Clinical Psychology, 39, 308-321.

Zuckerman, M., Eysenck, S. B. G., \& Eysenck, H. J. (1978). Sensation seeking in England and America: Cross-cultural, age, and sex comparisons. Journal of Consulting and Clinical Psychology, 46, 139-149.

Zuckerman, M., \& Neeb, M. (1980). Demographic influences in sensation seeking and expressions of sensation in religion, smoking, and driving habits. Personalicy and Individual Differences, 1, 197-206.

Zuckerman, M.,, Tushup, R., \& Finner, S. (1976). Sexual attitudes and experience: Attitude and personality correlates and changes produced by a course in sexuality. Journal of Consulting and Clinical Psychology, 44, 7-19.

ReCEIVED October 26, 1989; REVISED October 16, 1990. 